Polymer Journal, Vol. 39, No. 8, pp. 853-860 (2007)

(C) 2007 The Society of Polymer Science, Japan

\title{
Conformational Transformation of $\operatorname{Poly}(\beta$-phenetyl-L-aspartate) in Block Copolymer with Polystyrene in 1,1,2,2-Tetrachloroethane
}

\author{
Tomomichi ITOH, ${ }^{\dagger}$ Toshihiro IwAI, Eiji IHARA, and Kenzo INOUE ${ }^{\dagger}$ \\ Department of Materials Science and Biotechnology, Graduate School of Science and Engineering, VBL, Ehime University, \\ 3 Bunkyo-cho, Matsuyama 790-8577, Japan
}

(Received April 24, 2007; Accepted May 18, 2007; Published July 3, 2007)

\begin{abstract}
Temperature dependences of conformations of poly ( $\beta$-phenethyl-L-aspartate) (PA) in block copolymer systems, in which polystyrene (PS) was attached to either N-terminus $\left(\mathrm{PA}_{n}-\mathrm{N}-\mathrm{PS}_{m}\right)$ or C-terminus $\left(\mathrm{PS}_{n}-\mathrm{C}-\mathrm{PA}_{m}\right)$ of the PA, respectively, were investigated in 1,1,2,2-tetrachloroethane (TCE) solutions by using ${ }^{1} \mathrm{H}$ NMR spectroscopy. The block copolymers were synthesized by combination of atom transfer radical polymerization and ring-opening polymerization of $N$-carboxy amino acid anhydride. Whereas PA homopolymer $\left(\mathrm{H}_{-} \mathrm{PA}, n=68\right)$ with right-handed helical conformation started to transform to left-handed structure at $70^{\circ} \mathrm{C}$, the helical-sense inversion of $\mathrm{PA}_{68}-\mathrm{N}-\mathrm{PS}_{38}$ occurred at a lower temperature, $40^{\circ} \mathrm{C}$. Further transformation from left-handed conformation was not observed for both polymers in the temperature range of $70^{\circ} \mathrm{C}$ to $110^{\circ} \mathrm{C}$. On the other hand, ${ }^{1} \mathrm{H}$ NMR spectra of $\mathrm{PS}_{70}-\mathrm{C}-\mathrm{PA}_{170}$ showed coexistence of right- and left-handed helices of PA at 8.2 and $8.8 \mathrm{ppm}$ at $30^{\circ} \mathrm{C}$, respectively. These peaks, however, disappeared above $90^{\circ} \mathrm{C}$, and a new peak at $8.5 \mathrm{ppm}$ was observed. Thus, the introduction of PS chain into PA termini affected conformational stability of PA in a different way, although the transformational behaviors were not influenced by the difference of the chain length of PS segments. [doi:10.1295/polymj.PJ2007020]

KEY WORDS Poly $(\beta$-phenethyl-L-aspartate) / Block Copolymer / Helical-Sense Inversion / Chain Terminus / NMR /
\end{abstract}

Controlling the higher ordered structure of polymers is one of the most important factors for producing functional polymeric materials. In that context, polypeptides have been frequently investigated and utilized because they can assume various higher ordered structures. For example, poly(aspartate ester)s are known to form various conformations including right-handed helix (RH), left-handed helix (LH), $\beta$ sheet, and random coil (RC) depending on structure of side-chain groups, temperature, and solvents. ${ }^{1-13}$ In particular, RH and LH conformations are interesting because their formation can be reversibly controlled by thermal stimulus. ${ }^{5-8}$ The helical-sense inversion has been reported to be caused by difference in the conformational entropy of the side-chain between the two opposite helical structures. ${ }^{9-13}$

In addition to the side-chain groups, chain termini of poly(aspartate ester)s should have a significant effect on their conformations, thus, allowing us to control them. Although a number of reports addressing the effect has been limited so far, Ushiyama et al. have demonstrated that attaching helical poly $(\gamma$-benzyl-L-glutamate) (BG) segment at the chain terminus of $\operatorname{poly}(\beta$-phenethyl-L-aspartate) (PA) by block copolymerization have a significant influence on the helical-sense inversion of the PA segment. ${ }^{14}$ Thus, it would be intriguing if we can use other polymer seg- ment in place of the BG, because then more detailed analysis will become possible without undesirable overlapping of the signals in instrumental measurements such as CD, IR, X-ray, and NMR.

As a method for such block copolymerizations, a combination of ring-opening polymerization (ROP) of $N$-carboxy amino acid anhydride (NCA) ${ }^{15}$ and atom transfer radical polymerization (ATRP) ${ }^{16}$ of vinyl monomers has been demonstrated to be quite effective. For example, amino-terminated poly(methyl methacrylate) (PMMA) ${ }^{17}$ and polystyrene (PS) ${ }^{18}$ prepared via ATRP were used as macroinitiators for ROP of NCA to afford PMMA- or PS-polypeptide block copolymers with well-defined structure, which was given by living character for the two types of the polymerization. Whereas the PMMA or PS segment was attached C-terminus of the polypeptide segments, block copolymers having the conjugation point at polypeptides' N-terminus were also prepared by initiating the ATRP from polypeptide macroinitiators whose $\mathrm{N}$-terminus was capped with halogens. ${ }^{19-21}$

In this paper, the block copolymerization method is applied for PA for the first time and the effect of PS segment at $\mathrm{N}$ - and C-termini on conformational transformations of PA in 1,1,2,2-tetrachloroethane (TCE) is estimated from ${ }^{1} \mathrm{H}$ NMR spectra.

${ }^{\dagger}$ To whom correspondence should be addressed (E-mail: titou@eng.ehime-u.ac.jp, inoue@eng.dhime-u.ac.jp). 


\section{EXPERIMENTAL}

\section{Materials}

Triethylamine (TEA), tetrahydrofuran (THF), chloroform, and styrene (Nacalai, 98\%) were purified by conventional methods before use. 2-Bromoisobutyrylbromide (Aldrich, 98\%), tert-butylamine (TCI, 98\%), $\mathrm{CuBr}$ (Wako, 95\%), (-)-spartein (TCI, 95\%), phthalimide potassium salt (Nacalai, 98\%), hydrazine monohydrate (Nacalai, 80\%), and anisole (Wako, 95\%) were used as received.

\section{Characterization}

Molecular weight $\left(M_{\mathrm{n}}\right)$ and molecular weight distribution $\left(M_{\mathrm{w}} / M_{\mathrm{n}}\right)$ of PS precursors were measured by means of gel permeation chromatography (GPC) on a Jasco-Bowin system (ver. 1.50) equipped with PS calibrated Tosoh TSKgel $\left(\mathrm{G} 3000 \mathrm{H}_{\mathrm{HR}}, \mathrm{G} 4000 \mathrm{H}_{\mathrm{HR}}\right.$, and $\mathrm{G} 6000 \mathrm{H}_{\mathrm{HR}}$ ) using THF as an eluent. GPC spectra for $\mathrm{H}_{-}-\mathrm{PA}_{n}$ and PA block copolymers were also detected with TSKgel $\mathrm{G} 4000 \mathrm{H}_{\mathrm{XL}}$ using chloroform as an eluent.

${ }^{1} \mathrm{H}(400 \mathrm{MHz})$ NMR spectra were recorded on a Brucker Avance 400 spectrometer. 10\% of trifluoroacetic acid (TFA)- $\mathrm{CDCl}_{3}$ solutions were measured to determine $M_{\mathrm{n}}$ of PA in $\mathrm{H}-\mathrm{PA}_{n}$ and block copolymers on the basis of initiators. For conformational studies of PA segment, TCE- $d_{2}$ solutions, in which $2 \%$ of PA segments were dissolved and then placed overnight, were measured at various temperatures between 30 and $110^{\circ} \mathrm{C}$ under dry nitrogen.

\section{Synthesis of $P A_{n}-N-P S_{m}$}

H-PA $_{68}\left(M_{\mathrm{n}}=15000\right)$ was synthesized by a standard ROP of $N$-carboxy- $\beta$-phenethyl-L-aspartate anhydride (PLA-NCA) using tert-butylamine as an initiator in dry chloroform at room temperature. ${ }^{15}$ Then 2 bromoisobutyrylbromide $(2.0 \mathrm{~mL}, 8.6 \mathrm{mmol})$ was added dropwise to the ice-cooled dry chloroform solution of the $\mathrm{H}-\mathrm{PA}_{68}(2.4 \mathrm{~g}, 0.19 \mathrm{mmol})$ and dry TEA $(4.2$ $\mathrm{mL}, 17.3 \mathrm{mmol})$. The reaction was warmed to room temperature, stirred for $12 \mathrm{~h}$, and concentrated by evaporation. $\mathrm{PA}_{68}-\mathrm{Br}$ was reprecipitated from methanol for several times and thoroughly dried.

A mixture of styrene $(5.2 \mathrm{~g}, 50 \mathrm{mmol}), \mathrm{PA}_{68}-\mathrm{Br}$ $(1.5 \mathrm{~g}, 0.10 \mathrm{mmol}), \mathrm{CuBr}(14 \mathrm{mg}, 0.10 \mathrm{mmol}),(-)-$ spartein $(47 \mathrm{mg}, 0.20 \mathrm{mmol})$, and anisole $(12 \mathrm{~g})$ was divided into two glass tubes, degassed, sealed off under vacuum, and placed at $110^{\circ} \mathrm{C}$ for $4 \mathrm{~h}$ and $6 \mathrm{~h}$, respectively. The polymeric mixtures were diluted with THF, passed through neutral alumina, and evaporated. Two $\mathrm{PA}_{68}-\mathrm{N}-\mathrm{PS}_{m} \mathrm{~s}$ were reprecipitated from methanol and thoroughly dried. ${ }^{1} \mathrm{H}$ NMR $\left(10 \%\right.$ TFA-CDCl $\left.{ }_{3}\right)$; $\delta=8.0(\mathrm{~s}, \mathrm{~N} H, 1 \mathrm{H}), 7.3-7.1(\mathrm{~m}$, aromatic $H), 4.8$ (s, $\left.\mathrm{C}^{\alpha} \mathrm{H}, 1 \mathrm{H}\right), 4.3\left(\mathrm{~m}, \mathrm{O}-\mathrm{C}^{\varepsilon} H_{2}-\mathrm{C}^{\zeta} \mathrm{H}_{2}, 2 \mathrm{H}\right), 2.9$ (s, $\left.\mathrm{C}^{\beta} \mathrm{H}_{2}, 2 \mathrm{H}\right), 2.8$ (t, benzyl $\left.\mathrm{CH}_{2}, 2 \mathrm{H}\right)$ for PA segment and 7.3-7.1 (m, aromatic $H), 6.6(\mathrm{br}$, aromatic $H, 2 \mathrm{H})$, 1.9 (br, $\left.\mathrm{CH}_{2}-\mathrm{CH}, 1 \mathrm{H}\right), 1.5$ (br, $\mathrm{CH}_{2}-\mathrm{CH}, 2 \mathrm{H}$ ) for PS segment, respectively.

\section{Synthesis of $P S_{n}-C-P A_{m}$}

A bromo-terminated PS homopolymer $\left(\mathrm{PS}_{93}-\mathrm{Br}\right)$ $\left(M_{\mathrm{n}}=9700, \quad M_{\mathrm{w}} / M_{\mathrm{n}}=1.08\right)$ was synthesized by ATRP. ${ }^{16}$ A solution of the $\mathrm{PS}_{93}-\mathrm{Br}(1.4 \mathrm{~g}, 0.14 \mathrm{mmol})$ and phthalimide potassium salt $(0.32 \mathrm{~g}, 1.6 \mathrm{mmol})$ in dimethylformamide (DMF) $(80 \mathrm{~mL})$ was stirred at room temperature for $24 \mathrm{~h}$ under dry nitrogen and concentrated. The residue was dissolved in chloroform and washed two times with $5 \% \mathrm{NaOH}$ aqueous solution and further two times with water. The chloroform solution was dried with $\mathrm{MgSO}_{4}$, filtrated, and concentrated. Obtaining $\mathrm{PS}_{93}$-phthalimide was reprecipitated from methanol and thoroughly dried. The $\mathrm{PS}_{93}$-phthalimide and large amount of hydrazine monohydrate $(60 \mathrm{~mL})$ were dissolved in THF $(100 \mathrm{~mL})$, stirred at $45^{\circ} \mathrm{C}$ for $24 \mathrm{~h}$, and evaporated in order to precipitate polymer. Residual hydrazine was removed by decantation. The product was dissolved to THF and reprecipitated from methanol. $\mathrm{PS}_{93}-\mathrm{NH}_{2}$ was further purified by column chromatography in order to eliminate residual $\mathrm{PS}_{93}-\mathrm{Br}$ and $\mathrm{PS}_{93}$-phthalimide and then by reprecipitation for several times. Yield; $370 \mathrm{mg}(0.037$ mol, 26\%).

A mixture of PLA-NCA $(1.06 \mathrm{~g}, 4.02 \mathrm{mmol})$, the $\mathrm{PS}_{93}-\mathrm{NH}_{2} \quad$ (370 mg, $0.037 \mathrm{mmol}$ ), and chloroform $(80 \mathrm{~mL})$ was charged into a flask and stirred for $36 \mathrm{~h}$. The $\mathrm{PS}_{93}-\mathrm{C}-\mathrm{PA}_{55}$ was reprecipitated from dieth$\mathrm{yl}$ ether for several times in order to remove residual monomer and inactivated macroinitiator $\mathrm{PS}_{93}-\mathrm{NH}_{2}$ and thoroughly dried. Yield; $317 \mathrm{mg}(0.015 \mathrm{mmol}$, 22\%). ${ }^{1} \mathrm{H}$ NMR (10\% TFA-CDCl 3 ); $\delta=8.0$ (s, NH, $1 \mathrm{H}), 7.3-7.1(\mathrm{~m}$, aromatic $H), 4.8\left(\mathrm{~s}, \mathrm{C}^{\alpha} H, 1 \mathrm{H}\right), 4.3$ (m, O-C $\left.\mathrm{C}^{\varepsilon} \mathrm{H}_{2}-\mathrm{C}^{\zeta} \mathrm{H}_{2}, 2 \mathrm{H}\right), 2.9\left(\mathrm{~s}, \mathrm{C}^{\beta} \mathrm{H}_{2}, 2 \mathrm{H}\right), 2.8(\mathrm{t}$, benzyl $\mathrm{CH}_{2}, 2 \mathrm{H}$ ) for PA segment and 7.3-7.1 (m, aromatic $H$ ), 6.6 (br, aromatic $H, 2 \mathrm{H}), 1.9$ (br, $\mathrm{CH}_{2}-$ $\mathrm{CH}, 1 \mathrm{H}), 1.5\left(\mathrm{br}, \mathrm{CH}_{2}-\mathrm{CH}, 2 \mathrm{H}\right)$ for PS segment, respectively.

\section{RESULTS AND DISCUSSION}

Synthesis of block copolymers comprising PA and PS

Two types of block copolymers modified at $\mathrm{N}$ - and C-termini of PA with PS, $\mathrm{PA}_{n}-\mathrm{N}-\mathrm{PS}_{m}$ and $\mathrm{PS}_{n}-\mathrm{C}-\mathrm{PA}_{m}$, respectively, were prepared by a combination of ROP of PLA-NCA and ATRP of styrene (Scheme 1). For the synthesis of $\mathrm{PA}_{n}-\mathrm{N}-\mathrm{PS}_{m} \mathrm{~s}$, a terminal amino group of a PA homopolymer ( $\mathrm{H}_{-} \mathrm{PA}_{n}, n=68$; initiator, tertbutylamine) was converted into a bromide group $\left(\mathrm{PA}_{68}-\mathrm{Br}\right)$ by the reaction with 2-bromoisobutyrylbro- 
<smiles>O=C(CC1NC(=O)OC1=O)OCCc1ccccc1</smiles>

PLA-NCA

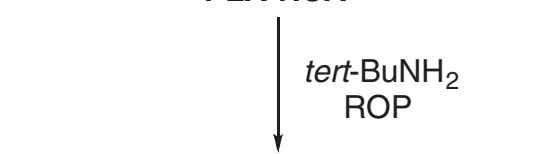<smiles>CC(N=P)C(=O)NC(C)(C)C</smiles><smiles>CC(=O)OCCCc1ccccc1</smiles>

$$
\text { H-PA }
$$
2-bromoisobutyrylbromide<smiles>CC(NC(=O)C(C)(C)Br)C(=O)NC(C)(C)C</smiles><smiles>O=COCCCc1ccccc1</smiles>

$\mathrm{PA}_{n}-\mathrm{Br}$

Styenre

ATRP<smiles>CC(C)(CC(=O)NC(C)(C)C(C)(C)C)C(=O)NC(CC(=O)OCCc1ccccc1)[N+](=O)C(C)(C)C</smiles>

$\mathrm{PA}_{n}-\mathrm{N}-\mathrm{PS}_{m}$<smiles>C=Cc1ccc(CC(C)(C)C(C)(Br)c2ccccc2)cc1</smiles>

$\mathrm{PS}-\mathrm{Br}$

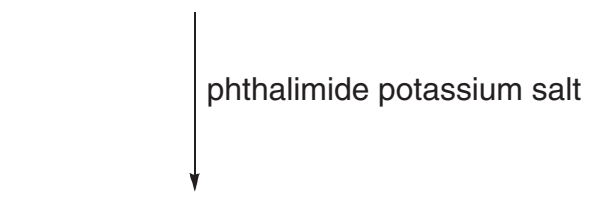<smiles>O=C1c2ccccc2C(=O)N1Cc1ccccc1</smiles>

$\mathrm{NH}_{2} \mathrm{NH}_{2}$<smiles>[CH]CCN</smiles><smiles>c1ccccc1</smiles>

PS- $\mathrm{NH}_{2}$ $\downarrow \begin{aligned} & \text { PLA-NCA } \\ & \text { ROP }\end{aligned}$<smiles>[NH2+]=NC(CC(=O)OCCc1ccccc1)C(=O)NCc1ccccc1</smiles>

$\mathrm{PS}_{n}-\mathrm{C}-\mathrm{PA}_{m}$

Scheme 1. Synthesis of $\mathrm{PA}_{n}-\mathrm{N}-\mathrm{PS}_{m}$ and $\mathrm{PS}_{n}-\mathrm{C}-\mathrm{PA}_{m}$.

mide. GPC of the block copolymer obtained from polymerization of styrene with the $\mathrm{PA}_{68}-\mathrm{Br} / \mathrm{CuBr} /$ (-)-spartein system showed one peak in higher molecular weight region with rather broad molecular weight distribution (Figure 1a, $M_{\mathrm{w}} / M_{\mathrm{n}}=1.91$ ). This unexpected $M_{\mathrm{w}} / M_{\mathrm{n}}$ value can be accounted for by a ligand exchange of $\mathrm{Cu}$-center between (-)-spartein and the amide group of the PA backbone. ${ }^{19}$ In the ${ }^{1} \mathrm{H}$ NMR spectrum measured in a mixture of $10 \%$ TFA-CDCl 3 , along with the peaks deviated from PS segment, the signals for the $\mathrm{N} H$ and $\mathrm{C}^{\alpha} H$ protons appeared at 8.0 and $4.8 \mathrm{ppm}$, respectively, indicating the formation of RC in PA (Figure 1b). Weight fraction of each polymer segment was determined from integral ratio of resonances corresponding to aromatic $H(2 \mathrm{H})$ at $6.6 \mathrm{ppm}$ for the PS segment to $\mathrm{C}^{\varepsilon} H_{2}(2 \mathrm{H})$ at $4.3 \mathrm{ppm}$ for the PA segment, resulting in the ratio of 68:38 $(\mathrm{mol} / \mathrm{mol})$ PA/PS $\left(t_{\mathrm{p}}=4 \mathrm{~h}\right)$. As expected, block copolymer with higher content of PS segment (68:120 PA/PS) was obtained for $t_{\mathrm{p}}=6 \mathrm{~h}$. The $M_{\mathrm{n}} \mathrm{s}$ of com- 
prising polymer segments in the $\mathrm{PA}_{n}-\mathrm{N}-\mathrm{PS}_{m} \mathrm{~s}$ are summarized in Table I.

For the synthesis of $\mathrm{PS}_{n}-\mathrm{C}-\mathrm{PA}_{m} \mathrm{~s}, \mathrm{PS}_{n}-\mathrm{Br}$ prepared by ATRP was converted into $\mathrm{PS}_{n}-\mathrm{NH}_{2}$ by the reaction

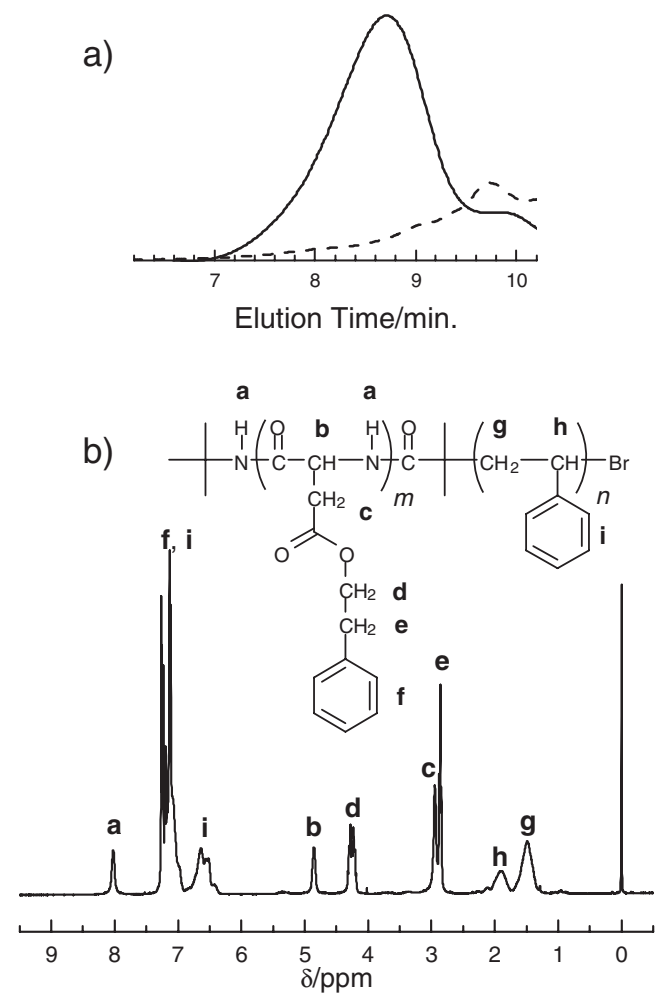

Figure 1. a) GPC charts and b) ${ }^{1} \mathrm{H}$ NMR signals for $\mathrm{PA}_{68}-\mathrm{N}-$ $\mathrm{PS}_{38}$, respectively. In the GPC charts which were observed with $\mathrm{CHCl}_{3}$ as an eluent, solid and dashed lines denote the block copolymer and the corresponding macroiniriator, respectively. For the ${ }^{1} \mathrm{H} \mathrm{NMR}$, the polymers dissolved in $10 \%$ TFA- $\mathrm{CDCl}_{3}$. of the $\mathrm{PS}_{n}$-Br with phthalimide potassium salt, followed by treatment with hydrazine (Scheme 1). We used the $\mathrm{PS}_{n}-\mathrm{NH}_{2}$ as a macroinitiator for ROP of PLA-NCA. Block copolymers were purified by reprecipitation from diethyl ether for elimination of residual monomer and inactivated macroinitiator. GPC charts for $\mathrm{PS}_{93}-\mathrm{C}-\mathrm{PA}_{55}$ showed a unimodal distribution $\left(M_{\mathrm{w}} / M_{\mathrm{n}}=1.15\right)$ and larger $M_{\mathrm{n}}$ than that of the $\mathrm{PS}_{93}-\mathrm{Br}$ (Figure 2). ${ }^{1} \mathrm{H}$ NMR spectra in the mixture of $10 \%$ TFA- $\mathrm{CDCl}_{3}$ showed signals and the chemical shifts were identical with those for the $\mathrm{PA}_{n}-\mathrm{N}-\mathrm{PS}_{m}$. These results indicate that $\mathrm{PS}_{93}-\mathrm{C}-\mathrm{PA}_{55}$ was successfully prepared by combination of ATRP and ROP of PLA-NCA. The $\mathrm{PS}_{n}-\mathrm{C}-\mathrm{PA}_{m} \mathrm{~s}$ with various $M_{\mathrm{n}} \mathrm{s}$ and weight fractions were also prepared as listed in Table II.

\section{Helical-sense inversion for $P A_{n}-N-P S_{m}$}

For characterizing the conformation of polypeptides in solutions, NMR is one of powerful tools; that is,

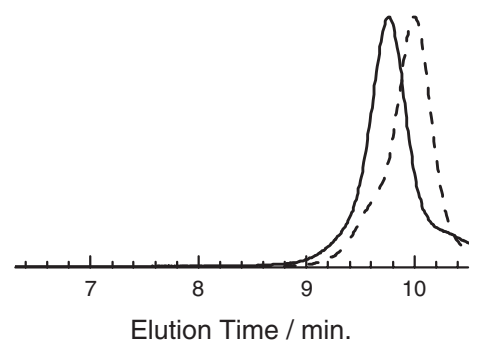

Figure 2. GPC charts for $\mathrm{PS}_{70}-\mathrm{C}-\mathrm{PA}_{170}$ (a solid line) and $\mathrm{PS}_{70}-\mathrm{Br}$ (a dashed line). Condition for the observation was the same as that in Figure 1.

Table I. Synthesis and characterization of $\mathrm{PA}_{n}-\mathrm{N}-\mathrm{PS}_{m} \mathrm{~s}^{\mathrm{a}}$

\begin{tabular}{ccccccc}
\hline Macroinitiator & $\begin{array}{c}\text { [Styrene]/ } \\
{[\mathrm{PA}-\mathrm{Br}]}\end{array}$ & $\begin{array}{c}\text { Conc. } / \\
\text { wt } \%\end{array}$ & Time $^{\mathrm{c}} / \mathrm{h}$ & $M_{\mathrm{n}, \mathrm{PA}} \times 10^{-3 \mathrm{~d}}$ & $M_{\mathrm{n}, \mathrm{PS}} \times 10^{-3 \mathrm{e}}$ & Block Copolymer \\
\hline $\mathrm{PA}_{68}-\mathrm{Br}$ & 500 & 33 & 4.0 & 15 & 4.0 & $\mathrm{PA}_{68}-\mathrm{N}_{-}-\mathrm{PS}_{38}$ \\
$\mathrm{PA}_{68}-\mathrm{Br}$ & 500 & 33 & 6.0 & 15 & 12 & $\mathrm{PA}_{68}-\mathrm{N}^{-\mathrm{PS}_{120}}$ \\
\hline
\end{tabular}

${ }^{a}$ Prepared by ATRP of styrene at $110{ }^{\circ} \mathrm{C}$. ${ }^{b}$ Concentration of the styrene diluted with anisole. ${ }^{c}$ Polymerization time. ${ }^{\mathrm{d}}$ Molecular weight of PA segment determined by ${ }^{1} \mathrm{H} \mathrm{NMR}$ in $\mathrm{CDCl}_{3}$ with addition of $10 \%$ of trifluoroacetic acid. ${ }^{\mathrm{e}}$ Molecular weight of PS segment determined by ${ }^{1} \mathrm{H}$ NMR on the basis of $M_{\mathrm{n}, \mathrm{PA}}$.

Table II. Synthesis and characterization of $\mathrm{PS}_{n}-\mathrm{C}-\mathrm{PA}_{m} \mathrm{~s}^{\mathrm{a}}$

\begin{tabular}{cccccc}
\hline Macroinitiator & {$[\mathrm{PLA}-\mathrm{NCA}] /\left[\mathrm{PS}-\mathrm{NH}_{2}\right]$} & $\mathrm{Time}^{\mathrm{b}} / \mathrm{h}$ & $M_{\mathrm{n}, \mathrm{PS}} \times 10^{-3 \mathrm{c}}$ & $M_{\mathrm{n}, \mathrm{PA}} \times 10^{-3 \mathrm{~d}}$ & $\begin{array}{c}\text { Block } \\
\text { Copolymer }\end{array}$ \\
\hline $\mathrm{PS}_{93}-\mathrm{NH}_{2}$ & 100 & 72 & 9.7 & 12 & $\mathrm{PS}_{93}-\mathrm{C}-\mathrm{PA}_{55}$ \\
$\mathrm{PS}_{70}-\mathrm{NH}_{2}$ & 100 & 72 & 7.3 & 36 & $\mathrm{PS}_{70}-\mathrm{C}-\mathrm{PA}_{170}$ \\
$\mathrm{PS}_{38}-\mathrm{NH}_{2}$ & 50 & 120 & 4.0 & 49 & $\mathrm{PS}_{38}-\mathrm{C}-\mathrm{PA}_{230}$ \\
$\mathrm{PS}_{70}-\mathrm{NH}_{2}$ & 100 & 170 & 7.3 & 98 & $\mathrm{PS}_{70}-\mathrm{C}-\mathrm{PA}_{450}$ \\
\hline
\end{tabular}

a Prepared by ring-opening polymerization of PLA-NCA using $\mathrm{PS}_{n}-\mathrm{NH}_{2}$ as macroinitiators at room temperature. Concentration of the PLA-NCA at $1 \%$ diluted with dry chloroform. ${ }^{b}$ Polymerization time. ${ }^{c}$ Molecular weight of PS segment determined by GPC measurements for $\mathrm{PS}_{n}$-Br precursors. ${ }^{\mathrm{d}}$ Molecular weight of PA segment determined by ${ }^{1} \mathrm{H}$ NMR measurement in $\mathrm{CDCl}_{3}$ with addition of $10 \%$ of trifluoroacetic acid on the basis of the $M_{\mathrm{n}, \mathrm{PS}}$. 

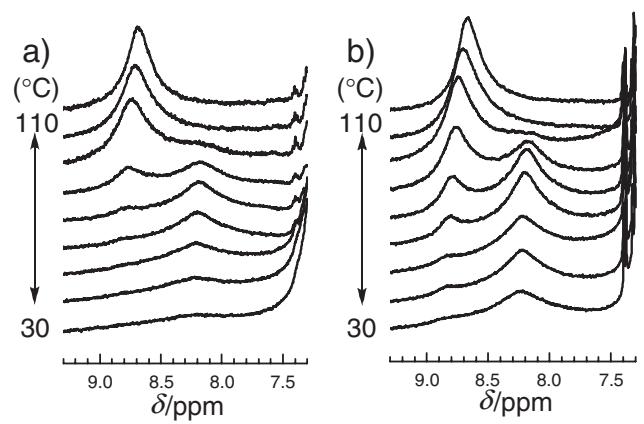

Figure 3. $\mathrm{N} H$ proton signals in ${ }^{1} \mathrm{H}$ NMR for a) $\mathrm{H}_{-} \mathrm{PA}_{68}$ and b) $\mathrm{PA}_{68}-\mathrm{N}-\mathrm{PS}_{38}$ in a dilute TCE- $d_{2}$ solution observed at various temperatures between 30 and $110^{\circ} \mathrm{C}$ in $10^{\circ} \mathrm{C}$ intervals, respectively.

$\mathrm{N} H$ proton signals are particularly useful to estimate their helical sense in PA. ${ }^{13,14}$ Figure $3 \mathrm{a}$ shows the $\mathrm{NH}$ proton signals for $\mathrm{H}_{-} \mathrm{PA}_{68}$, which was used for the synthesis of $\mathrm{PA}_{68}-\mathrm{N}-\mathrm{PS}_{m} \mathrm{~s}$, at various temperature from 30 to $110^{\circ} \mathrm{C}$ in $10^{\circ} \mathrm{C}$ intervals. At $30^{\circ} \mathrm{C}$, a signal was observed at $8.2 \mathrm{ppm}$, indicating the formation of $\mathrm{RH}$, and it became sharper above $40^{\circ} \mathrm{C}$. At $70^{\circ} \mathrm{C}$, another signal at $8.8 \mathrm{ppm}$ assignable to $\mathrm{LH}$ appeared and became sharper with further increasing temperature, whereas the RH signal became weaker and then disappeared above $100^{\circ} \mathrm{C}$. Any signals at $7.8 \mathrm{ppm}$ which are expected for RC were not observed in whole temperature region. The signals were completely reversible on heating and cooling cycles. The behaviors of the thermally reversible helical-sense inversion of $\mathrm{H}_{-} \mathrm{PA}_{68}$ were in good agreement with that reported in the literature. ${ }^{13}$

For $\mathrm{PA}_{68}-\mathrm{N}-\mathrm{PS}_{38}$ (Figure 3b), PA segment took RH but some residues form $\mathrm{LH}$ at $30^{\circ} \mathrm{C}$, as evidenced by the observation of a weak signal at $8.8 \mathrm{ppm}(\mathrm{LH})$. Again, the formation of RC was not observed. The content of LH increased with increasing temperature, and above $100^{\circ} \mathrm{C}$ all of the PA segments took LH in a manner similar to $\mathrm{H}_{-} \mathrm{PA}_{68}$. Figure 4 shows temperature dependence of the ratio for the $\mathrm{LH}$ to total $\mathrm{NH}$ peak area $\left(r_{\mathrm{LH}}=\mathrm{P}_{\mathrm{LH}} /\left(\mathrm{P}_{\mathrm{LH}}+\mathrm{P}_{\mathrm{RH}}\right)\right)$ for $\mathrm{H}-\mathrm{PA}_{68}$,

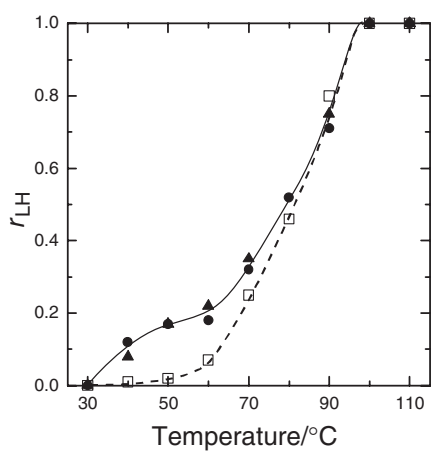

Figure 4. Temperature dependence of LH ratio to total integral of $\mathrm{NH}$ protons $\left(r_{\mathrm{LH}}\right)$ for $\mathrm{H}-\mathrm{PA}_{68}$ (open squares), $\mathrm{PA}_{68}-\mathrm{N}-\mathrm{PS}_{38}$ (filled circles), and $\mathrm{PA}_{68}-\mathrm{N}-\mathrm{PS}_{120}$ (filled triangles), respectively.
$\mathrm{PA}_{68}-\mathrm{N}-\mathrm{PS}_{38}$, and $\mathrm{PA}_{68}-\mathrm{N}-\mathrm{PS}_{120}$. The difference between the $\mathrm{PA}_{68}-\mathrm{N}-\mathrm{PS}_{m} \mathrm{~s}$ and the $\mathrm{H}-\mathrm{PA}_{68}$ became significant at $40{ }^{\circ} \mathrm{C}$ where the $r_{\mathrm{LH}}$ of the $\mathrm{PA}_{68}-\mathrm{N}-\mathrm{PS}_{38}$ was 0.12 , while that of the $\mathrm{H}_{-} \mathrm{PA}_{68}$ remained 0 . The $r_{\mathrm{LH}}$ of the $\mathrm{PA}_{68}-\mathrm{N}-\mathrm{PS}_{38}$ gently increased with elevating temperature, and then curves of the $r_{\mathrm{LH}}$ of $\mathrm{PA}_{68}$ - $^{-}$ $\mathrm{N}-\mathrm{PS}_{38}$ and $\mathrm{H}-\mathrm{PA}_{68}$ overlapped one another in the temperature range of 70 to $110^{\circ} \mathrm{C}$, suggesting that no significant influence of PS segments on conformation of PA was operative in this temperature range. Figure 4 also shows that transformational behavior was not influenced by chain length of PS segment in these $M_{\mathrm{n}}$ range. The overall changes of the $r_{\mathrm{LH}} \mathrm{S}$ for these polymers were completely reversible on heating and cooling cycles, indicating that the helical-sense inversion was governed by a thermodynamic equilibrium.

The most plausible explanation of the decrease of transformational temperature from $\mathrm{RH}$ to $\mathrm{LH}$ for $\mathrm{PA}_{68}-\mathrm{N}-\mathrm{PS}_{38}$ is that the $\mathrm{RH}$ formation was perturbed by the large chain mobility due to high solubility of PS segment in TCE. However, the gentle slope of the $r_{\mathrm{LH}}$ curve up to $60^{\circ} \mathrm{C}$ implies that the perturbation occurred in a limited from $\mathrm{N}$-terminus attaching PS. It appears that the counterbalance between the perturbation by the PS segment on N-terminus and the inherent $\mathrm{RH}$ formation of PA in C-terminal side is responsible for the decrease of transformation temperature. As described earlier, from the fact that the RC was not observed, it is safe to say that the RC does not contribute to transformation from $\mathrm{RH}$ to $\mathrm{LH}$ or vice versa. These mechanisms of the helical-sense inversions for the $\mathrm{H}-\mathrm{PA}_{68}$ and the $\mathrm{PA}_{68}-\mathrm{N}-\mathrm{PS}_{38}$ are schematically illustrated in Figure 5.

\section{Conformational transformation for $P S_{n}-C-P A_{m}$}

Figure 6a shows temperature dependence of $\mathrm{NH}$ proton signal for $\mathrm{PS}_{70}-\mathrm{C}-\mathrm{PA}_{170}$. At $30^{\circ} \mathrm{C}$, both $\mathrm{LH}$ and $\mathrm{RH}$ signals were observed with $r_{\mathrm{LH}}=0.24$, together with a weak shoulder of $\mathrm{RC}$ signal at $8.0 \mathrm{ppm}$. While main-chain $\mathrm{C}^{\alpha} \mathrm{H}$ and side-chain $\mathrm{C}^{\varepsilon} \mathrm{H}_{2}$ proton signals for $\mathrm{H}-\mathrm{PA}_{n}$ and $\mathrm{PA}_{n}-\mathrm{N}-\mathrm{PS}_{m}$ are difficult

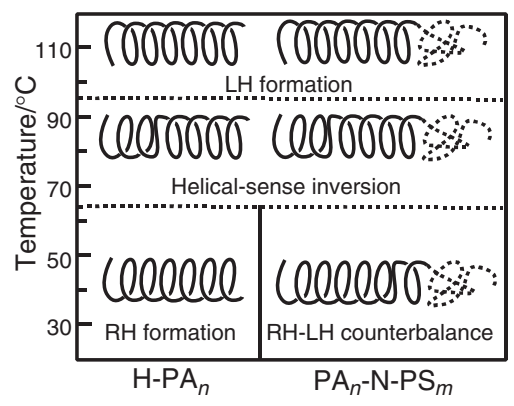

Figure 5. A schematic phase diagram of thermally induced conformational transformations for $\mathrm{H}-\mathrm{PA}_{n}$ and $\mathrm{PA}_{n}-\mathrm{N}-\mathrm{PS}_{m}$. 

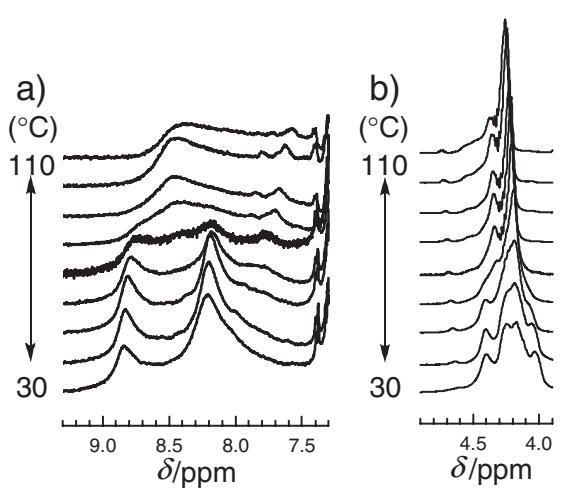

Figure 6. a) $\mathrm{N} H$ and b) $\mathrm{C}^{\alpha} H$ and $\mathrm{C}^{\varepsilon} H_{2}$ proton signals in ${ }^{1} \mathrm{H}$ NMR for $\mathrm{PS}_{70}-\mathrm{C}-\mathrm{PA}_{170}$ in a dilute TCE- $d_{2}$ solution observed at various temperatures between 30 and $110^{\circ} \mathrm{C}$ in $10^{\circ} \mathrm{C}$ intervals, respectively.

to be assigned because of their broadness and overlapping each other, characteristic signals of the mainchain $\mathrm{C}^{\alpha} H$ proton were observed for the $\mathrm{PS}_{70}-\mathrm{C}$ $\mathrm{PA}_{170}$ as shown in Figure $6 \mathrm{~b}$. The peaks observed at $4.25,4.40$, and $4.65 \mathrm{ppm}$ can be assigned to $\mathrm{RH}, \mathrm{LH}$ and $\mathrm{RC}$, respectively. Side-chain $\mathrm{C}^{\varepsilon} \mathrm{H}_{2}$ protons also showed signals at 4.05 and $4.20 \mathrm{ppm}$. For the $\mathrm{PS}_{70^{-}}$ C-PA 170 , the $r_{\mathrm{LH}}$ value of 0.24 was maintained up to $50^{\circ} \mathrm{C}$, indicating that $\mathrm{RH}$ and $\mathrm{LH}$ of the block copolymer were rather insensitive to the change of the temperature. However, with further increased of temperature, a very broad signal at $8.5 \mathrm{ppm}$ and weak one at $7.7 \mathrm{ppm}$ appeared, accompanied by disappearance of both the RH and LH signals. The main-chain $\mathrm{C}^{\alpha} H$ protons assigned to $\mathrm{RH}$ and $\mathrm{LH}$, naturally, disappeared, and new signals were observed at 4.35 and $4.55 \mathrm{ppm}$. Furthermore, side-chain $\mathrm{C}^{\varepsilon} \mathrm{H}_{2}$ protons also were affected by the temperature elevation, i.e., the increase of signal intensity at $4.25 \mathrm{ppm}$, indicating the formation of more proliferated side-chain conformations. ${ }^{9-13}$ Again the signals were completely reversible on heating and cooling cycles.

In the temperature range of 30 to $50^{\circ} \mathrm{C}$, similar coexistence of RH and LH was observed for other $\mathrm{PS}_{n^{-}}$ C-PA ${ }_{m}$ s listed in Table II. The results indicate that the attachment of PS segment at C-terminus brought about enhancement of the formation of LH. Figure 7 shows the dependence of $r_{\mathrm{LH}}$ on molecular weight of PA segment $\left(M_{\mathrm{n}, \mathrm{PA}}\right)$ for the $\mathrm{PS}_{n}-\mathrm{C}-\mathrm{PA}_{m} \mathrm{~s}$. The value became smaller with increasing $M_{\mathrm{n}, \mathrm{PA}}$, and reached 0.17 at $M_{\mathrm{n}, \mathrm{PA}}=98000$, whereas it can be seen that the relative content of LH was not influenced by chain length of PS segment in these $M_{\mathrm{n}}$ range. The result implies that the formation of LH induced by PS segment occurred in a limited from C-terminus. Furthermore, PA conformation would not be exchanged between RH and LH in this temperature region, because 2D-exchange spectra observed at room temper-

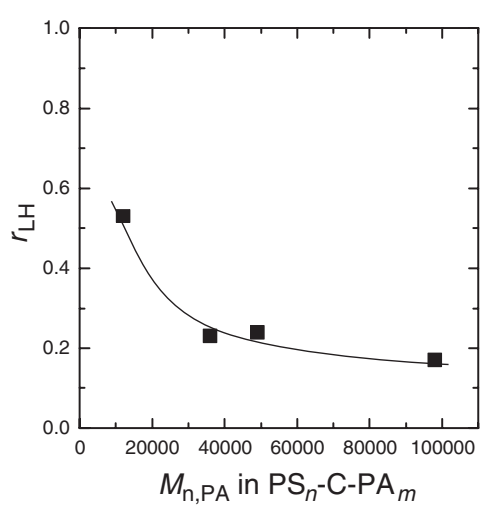

Figure 7. $M_{\mathrm{n}, \mathrm{PA}}$ dependence of $r_{\mathrm{LH}}$ for $\mathrm{PS}_{n}-\mathrm{C}-\mathrm{PA}_{m} \mathrm{~s}$ in a dilute $\mathrm{CDCl}_{3}$ solution.

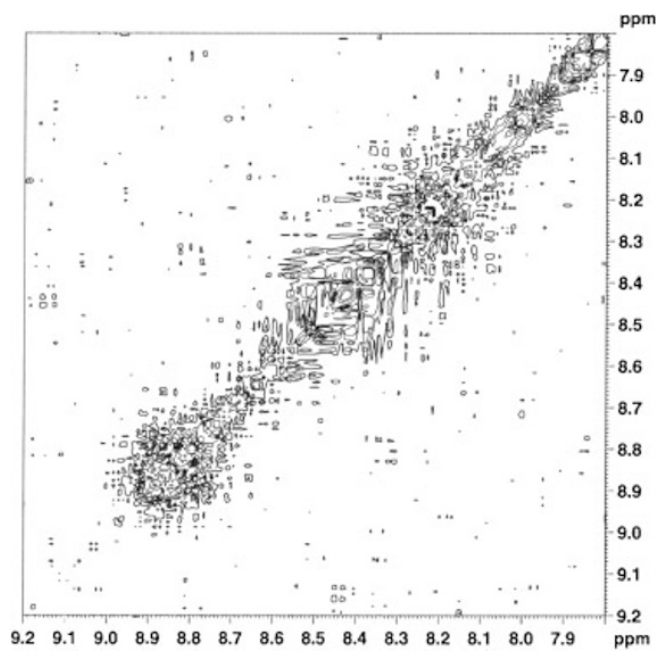

Figure 8. A $2 \mathrm{D}$ COSY spectrum for $\mathrm{N} H$ proton of $\mathrm{PS}_{70}-\mathrm{C}-$ $\mathrm{PA}_{170}$ in a dilute TCE- $d_{2}$ solution observed at room temperature.

ature did not show any cross signals of the two $\mathrm{NHs}$ for RH and LH (Figure 8).

As described above, RC signals at $8.0(\mathrm{NH})$ and $4.60 \mathrm{ppm}\left(\mathrm{C}^{\alpha} H\right)$ were observed over the temperature range examined, accompanied by the shift to upfield and downfield with increasing temperature, respectively, although both RH and LH were subjected to thermally induced transformation. Taking into considerations of the presence of RC and disappearance of both $\mathrm{RH}$ and $\mathrm{LH}$ at elevated temperatures, the residues that form RC seemed to exist in the connection part of PA with PS segment.

The conformation corresponding to the major signal at $8.5 \mathrm{ppm}$ has not been clarified at the present time. One can expect that very fast conformational exchange of RH and LH took place above $70^{\circ} \mathrm{C}$. However, the argument requires that the existence of $\mathrm{RH}$ in significant amounts even at further elevated temperature, in spite of the fact that RH stability is reduced by attached PS segment. Recently the formation of flexible-rod conformation has been proposed in lyotropic 


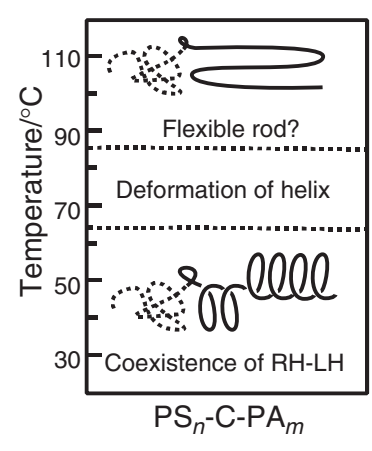

Figure 9. A schematic phase diagram of thermally induced conformational transformations for $\mathrm{PS}_{n}-\mathrm{C}-\mathrm{PA}_{m}$.

liquid crystalline state of PA homopolymer in the presence of small amount of TFA. ${ }^{13}$ Although the flexible-rod conformation has been unfamiliar thus far, we tentatively propose that the peak observed at $8.5 \mathrm{ppm}$ at elevated temperatures is ascribed to the formation of $\beta$-strand like conformation of $\mathrm{PS}_{n}-\mathrm{C}$ $\mathrm{PA}_{m} \mathrm{~s}$ (Figure 9). If formation of such conformation is involved, the precipitate of the block copolymers is expected to form due to intra- and/or intermolecular interactions. In fact, other work in progress by us includes demonstration that a star-shaped polymer comprising PA, where C-terminus of PA is attached to the core, is precipitated from TCE above the flexible-rod forming temperature. ${ }^{22}$ For $\mathrm{PS}_{n}-\mathrm{C}-\mathrm{PA}_{m} \mathrm{~s}$, however, any precipitations were not observed in the temperature range of 90 to $110^{\circ} \mathrm{C}$, suggesting that intermolecular hydrogen bonds might be negligibly weak even if the PA segment took the $\beta$-strand like conformation.

PS segment in $\mathrm{PS}_{n}-\mathrm{C}-\mathrm{PA}_{m} \mathrm{~S}$ induced unusual conformational behavior of PA, while inversion temperature of helical sense was lowered in $\mathrm{PA}_{n}-\mathrm{N}-\mathrm{PS}_{m} \mathrm{~s}$. The results showed that the conformational free energy in C-terminal side of PA would not be the same as that in $\mathrm{N}$-terminal side. Although the reason remains unclear, one possible explanation is that helix capping ${ }^{23}$ contributes to the difference between $\mathrm{N}$ - and C-termini. For $\alpha$-helical polypeptides and proteins, because the first four $\mathrm{NH}$ groups and the last four $\mathrm{CO}$ groups of helix necessarily lack intrahelical hydrogen bonds, polar side chains at the positions near the terminal ends of the helices are often able to form hydrogen bonds to these unfulfilled groups. ${ }^{23}$ Accordingly, it is assumable that the conformational free energy at $\mathrm{N}$-terminus of PA is altered by the helix capping with side-chain ester $\mathrm{CO}$ groups which can satisfy the uncompensated main-chain amide $\mathrm{NH}$ groups.

\section{SUMMARY}

Block copolymers comprising poly $(\beta$-phenethyl-L- aspartate) (PA) and polystyrene (PS) where the PS was attached to $\mathrm{N}$ - and $\mathrm{C}$-terminus of the $\mathrm{PA}$ in $\mathrm{PA}_{n}-\mathrm{N}-\mathrm{PS}_{m}$ and $\mathrm{PS}_{n}-\mathrm{C}-\mathrm{PA}_{m}$, respectively, were prepared by combination of ATRP and ROP of $\mathrm{N}$-carboxy amino acid anhydride. Conformational transformations of the PA in the block copolymer systems were studied in dilute 1,1,2,2-tetrachloroethane solutions at various temperatures. In the case of $\mathrm{PA}_{68}-\mathrm{N}-$ $\mathrm{PS}_{m} \mathrm{~s}$, the PS segment played a role to enhance the transformation from right-handed helical structure $(\mathrm{RH})$ to left-handed one ( $\mathrm{LH})$ in the temperature range of 40 to $60^{\circ} \mathrm{C}$, but at elevated temperatures the formation of LH seemed to be governed by inherent properties of PA. On the other hand, $\mathrm{PS}_{n}-\mathrm{C}-\mathrm{PA}_{m}$ showed different behaviors. $\mathrm{PS}_{n}-\mathrm{C}-\mathrm{PA}_{m}$ took both $\mathrm{RH}$ and $\mathrm{LH}$ formed at $30^{\circ} \mathrm{C}$. Interestingly, no further helical-sense inversion was induced by temperature changes between 30 and $50^{\circ} \mathrm{C}$, and then the helices were transformed into another conformation, which is tentatively assumed to be flexible-rod structure, at elevated temperatures. Thus, the modification of $\mathrm{N}$ - and C-terminus of PA brought about the formation of LH structure at relatively low temperatures. In addition, for the latter polymer extraordinary conformation was formed at elevated temperatures. The results indicate that each chain terminus of PA has different conformational free energy.

As can be seen in these PA block copolymer systems, block copolymerization with various polymer segments will lead control of conformational behavior in poly(aspartate ester)s as well as structure of sidechain groups, temperature, and solvents.

\section{REFERENCES}

1. E. R. Blout and R. H. Karlson, J. Am. Chem. Soc., 80, 1259 (1958).

2. M. Goodman and F. Boardman, J. Am. Chem. Soc., 85, 2491 (1963).

3. M. Hashimoto and S. Arikawa, Bull. Chem. Soc. Jpn., 40, 1698 (1967).

4. E. M. Bradbury, B. G. Carpenter, and H. Goldman, Biopolymers, 6, 837 (1968).

5. J. Watanabe, S. Okamoto, K. Satoh, K. Sakajiri, H. Furuya, and A. Abe, Macromolecules, 29, 7084 (1996).

6. K. Sakajiri, K. Satoh, S. Kawauchi, and J. Watanabe, J. Mol. Struct., 476, 1 (1999).

7. J. Watanabe, S. Okamoto, and A. Abe, Liq. Cryst., 15, 259 (1993).

8. A. Abe, S. Okamoto, N. Kimura, K. Tamura, H. Onigawara, and J. Watanabe, Acta. Polym., 44, 54 (1993).

9. J. F. Yan, G. Vanderkooi, and H. A. Sheraga, J. Chem. Phys., 49, 2713 (1968).

10. H. Mayama, T. Hiraoki, and A. Tsutsumi, Rep. Prog. Polym. Phys. Jpn., 37, 567 (1994).

11. A. Abe and S. Okamoto, Rep. Prog. Polym. Phys. Jpn., 36, 517 (1993). 


\section{T. Ітон et al.}

12. S. Okamoto, H. Furuya, and A. Abe, Polym. J., 27, 746 (1995).

13. A. Abe, H. Furuya, and S. Okamoto, Biopolymers (Peptide Science), 43, 405 (1997).

14. A. Ushiyama, H. Furuya, A. Abe, and T. Yamazaki, Polym. J., 34, 450 (2002).

15. W. H. Daly and D. Poche, Tetrahedron Lett., 29, 5859 (1988).

16. K. Matyjaszewski and J. Xia, Chem. Rev., 101, 2921 (2001).

17. K. R. Brzezinska and T. J. Deming, Macromol. Biosci., 4, 566 (2004).
18. S. Abraham, C. S. Ha, and I. Kim, J. Polym. Sci., Part A: Polym. Chem., 44, 2774 (2006).

19. H. Rettig, E. Krause, and H. G. Börner, Macromol. Rapid Commun., 25, 1251 (2004).

20. Y. Mei, K. L. Beers, H. C. M. Byrd, D. L. VanderHart, and N. R. Washburn, J. Am. Chem. Soc., 126, 3472 (2004).

21. M. L. Becker, J. Liu, and K. L. Wooley, Biomacromolecules, 6, 220 (2005).

22. Y. Mitsuta, T. Itoh, E. Ihara, and K. Inoue, Polym. Prepr., Jpn., 56, 2032 (2007).

23. R. Aurora and G. D. Rose, Protein Sci., 7, 21 (1998). 